\title{
El cine de Óscar Campo: memoria de la violencia en Colombia desde el documental del disenso.
}

\section{Óscar Campo's Cinema: Memory of Violence in Colombia from the Documentary of Dissent.}

\section{Resumen}

El siguiente artículo habla sobre la existencia de un cine documental colombiano que trabaja desde el disenso y se propone como espacio político, entendiéndose el concepto de político como la intersección entre el poder y la resistencia donde se genera el debate, como lo propone Jacques Rancière. Es un cine que busca desarticular el orden consensual de la narración histórica predominante en Colombia y se caracteriza por desarrollarse en la marginalidad y plantear la creación desde la comprensión de los acuerdos consensuados, los que luego son tomados como argumentos de discusión.

Desde mediados del siglo pasado Colombia está sumida en la violencia procedente de diferentes frentes. Los medios de comunicación se han encargado de difundir y respaldar públicamente los distintos acuerdos de poder. En ese entorno, esta investigación busca responder ¿cómo se logra dislocar el consenso público y construir una memoria disidente que sobreviva a la saturación de discursos que circulan en torno a la violencia en Colombia? Para ello se analizará el trabajo del director de cine Óscar Campo como representativo de esta propuesta. Su obra compone una gama de narrativas que, aunque diferentes entre sí, mantienen cierta cohesión y progresión comunes en un relato que intenta crear criterios estético-políticos no convencionales de la violencia de Colombia de los últimos años.

Palabras claves Documental, disenso, memoria, violencia, arte marginal, transnacional, Óscar Campo, Colombia. 


\section{Abstract}

The following article discusses the existence of an Colombian documentary film which works from the aesthetics of dissent and proposes to art as a political space, understood the concept of politician as the intersection between power and resistance where the debate it generates, as proposed by Jacques Rancière. They are films that seek to create a disarticulation in the consensual order of historical narration that prevails in Colombia and are characterized by developed in marginality and pose creation from the compression of the consensus agreements to have arguments for discussion.

Colombia since the mid of the last century is mired in violence coming from different fronts, media have been commissioned to disseminate and publicly support power agreements. In this environment, this research seeks to respond: how is accomplished dislocate the public consensus and build a dissenting memory that survives to the saturation of the discourses circulating around violence in Colombia?

This paper will discuss the work of the Colombian director Óscar Campo as representative of this proposal. His work comprises a range of narratives which, although they are different each other, they maintain some cohesion and progression in a story that manages to create unconventional political - aesthetic criteria of Colombian violence.

Keywords

Documentary, dissent, memory, violence, marginal art, transnational, Óscar Campo, Colombia.

Pero ¿Cómo impartir conocimiento en alguien que se niega a conocer?

¿Cómo abrir los ojos? ¿Cómo desarmar las defensas, las protecciones, los estereotipos, la mala voluntad, las políticas de avestruz de quien no quiere saber? Es con esta pregunta siempre en mente que Farocki considera el problema de toda su película.

Es con esta pregunta en mente que su mirada vuelve a la lente de la cámara y Farocki pasa a la acción.

(Didi-Huberman. Desconfiar de las imágenes)

\section{Introducción}

El inicio de los conflictos contemporáneos en Colombia está marcado por el asesinato del líder político Jorge Eliécer Gaitán, el 9 de abril de 1948. Desde entonces una espiral de violencia envuelve a la sociedad. Cada nuevo gobernante llegado al poder se impone como meta acabar durante su mandato al menos con 
CATEDRAL Tomada: Revista de crítica literaria latinoamericana / Journal of Latin American Literary Criticism

El cine de Óscar Campo: memoria de la violencia en Colombia desde el documental del disenso.

una de las violencias ${ }^{1}$ instauradas en el país. Es así como, tras décadas de intentos de negociación, millones de desplazados y miles de desaparecidos y asesinados, en 2016 el Estado logra concretar el llamado proceso de paz con el grupo subversivo más importante y antiguo de Colombia, lo que aparentemente atenúa el conflicto armado y da paso a la era del llamado posconflicto. Se abre así la posibilidad de que las futuras generaciones de colombianos puedan ver, desde su perspectiva, estas épocas de barbarie como una marca significativa del pasado, lo que nos lleva a preguntarnos ¿cuáles serán las imágenes, sonidos y textos relatores de esa realidad que lograrán sobrevivir al paso del tiempo?

Tras los eventos traumáticos por los que atravesó la humanidad durante el siglo pasado, en la década de los 90 se generó una cultura global en torno a la defensa de los derechos humanos y a la no repetición. Se instauraron intensas políticas en torno a un discurso público sobre la memoria que buscan exponer, desde diversas miradas, historias de barbarie contemporáneas. A esto se respondió con una saturación de actos conmemorativos, por un lado, y con la circulación compulsiva de imágenes de los conflictos, gracias a la capacidad ilimitada que tiene el material audiovisual de ser proyectado y archivado:

El giro hacia la memoria recibe un impulso subliminal del deseo de anclarnos en un mundo caracterizado por una creciente inestabilidad del tiempo y por la fracturación del espacio en que vivimos. Al mismo tiempo, sabemos que incluso este tipo de estrategias de memorialización pueden terminar siendo transitorias e incompletas [...]. (Huyssen 24)

${ }^{1}$ Aunque la palabra violencias no existe en el diccionario de lengua española, en Colombia, al igual que en diferentes países con conflictos, se utiliza para referirse a la diversidad de orígenes y características de la violencia que a veces son consecutivos y otras, se solapan. Uno de los textos que recopila las diferentes deficiones de ésta es: González, Fernán. La violencia política y las dificultades de la construcción de lo público en Colombia: una mirada de larga duración. En: Jaime Arocha, Fernando Cubides y Myriam Jimeno (Comp.), Las violencias: inclusión creciente. Bogotá: Centro de Estudios Sociales, Universidad Nacional de Colombia, 1998. 
Las políticas oficiales y de las diversas fuerzas sociales de Colombia no han sido ajenas a estas tendencias mundiales. Con una narración, que se hace en simultaneidad a la ocurrencia de los acontecimientos, los medios de comunicación, subordinados a estamentos de poder político y económico, emiten de manera compulsiva y superflua imágenes e historias de la barbarie. Esto ha generado un hiper-consumo de referencias de la violencia que genera, por un lado, una rutinización (GMH 14) que desvirtúa la búsqueda de la construcción de la memoria y por otro, miedo y paranoia al interior de la sociedad, lo que ha conducido a que ésta justifique y hasta respalde la existencia de la guerra en el país.

Como respuesta al discurso hegemónico y a la demanda de darle un nuevo sentido a la creación, surge en el arte un viraje en la producción y asume prácticas de carácter simbólico que, según el sociólogo Elkin Rubiano, son las que ayudan a procesar la ruptura y recomponer el ethos grupal destruido a causa del trauma social generado por la violencia. Es así como obras provenientes de diferentes disciplinas han logrado construir un entramado de imágenes y narraciones de la realidad del país, con posturas disidentes que abren paso al debate en el espacio político y visibilizan el interrogante, que inquieta a los colombianos, sobre qué promueve la existencia y persistencia de la barbarie en el país. El cine documental ha sido una de las expresiones artísticas que se ha fortalecido en los últimos años y ha creado desde la emancipación y con una perspectiva crítica un espacio de resistencia. A finales de los años 90 surge un cine documental libre de las narrativas y formas de producción dominantes que propone, desde la marginalidad, un debate abierto sobre la realidad del país. Este cine, al que llamaremos documental del disenso, no está establecido ni cohesionado ya que ha estado en un estado de preformación y emergencia en bolsas dispares y dispersas.

Desde este punto de partida, el siguiente artículo plantea la hipótesis de que el relato que hace el documental del disenso de la realidad puede producir la dislocación del espacio-tiempo y conducir a un entendimiento diferente a lo que brindan los medios de comunicación y la historia oficial, con lo cual surge la 
CATEDRAL TOMADA: Revista de crítica literaria latinoamericana / Journal of Latin American Literary Criticism

El cine de Óscar Campo: memoria de la violencia en Colombia desde el documental del disenso.

posibilidad de generar una memoria reflexiva que conduzca al cambio: "Una estética del disenso, así propuesta, está menos pendiente de oposiciones consensuales (dentro/fuera; visible/invisible, etc.) y más atenta a las posibilidades de circulación, el borramiento de fronteras y la permanente reconstrucción de la realidad y la ficción" (Niño 73).

\section{El consenso y el disenso}

Para entender lo que es el documental del disenso, convengamos en tomar la definición de consenso del filósofo francés Jacques Rancière que dice que es el acto de sumisión ante un acuerdo llegado entre los diferentes frentes, sus formas de representación y su interpretación. Supone una configuración en la que todo está definido de antemano, en palabras del filósofo: "[...] significa el acuerdo sobre los datos sensibles de una situación, sobre las maneras de interpretar las causas y de deducir las formas de acción posibles" (Política 8). Según Rancière, el consenso que aparece con la caída del comunismo y el resurgimiento de la democracia, que es el que se mantiene vigente, es responsable de que la política se haya convertido en una actividad lacónica de negociación en la que han dejado por fuera del acuerdo a "actores de dudosa reputación" (Rancière, Sobre 9), entre los que probablemente se encuentran los documentalistas del disenso, quienes tendrían las herramientas para proponer un espacio-tiempo diferente que reestructure el orden establecido y plantee un desacuerdo. Es la capacidad que tiene el documental de lograr, a través de la provocación y el extrañamiento, la pérdida progresiva de la conciencia habitual del espectador y perturbar las lógicas de control que Rancière denomina como «policial» "[...] lo propio del arte consiste en practicar una distribución nueva del espacio material y simbólico. Y es por ahí por donde el arte tiene que ver con la política" (Rancière, Sobre 17). El filósofo dice que el espacio primigenio de la política debería ser el del disenso, o sea, el de la confrontación de argumentos y el de la irrupción dentro del espacio 
público de aquellas partes que no estaban representadas en los acuerdos consensuados y que exigen ser escuchadas con sus propios mecanismos de discusión, información y formación.

En el caso particular de Colombia, el arte ha venido acompañando el devenir de la realidad violenta del país durante casi siete décadas, trabajando de manera crítica y afanosa; desde las artes plásticas con pinturas como "Violencia" (1962) de Alejandro Obregón, hasta el cine y las artes visuales con producciones como "Todos tus muertos" (2011) de Carlos Moreno y las instalaciones de Alejandro Restrepo, destacando su última exhibición "Religión Catódica” (2017). Vistas de manera retrospectiva, estas obras han logrado construir desde la estética una versión alternativa de la historia reciente del país. Es lo que Rancière define como "las formas de visibilidad de las prácticas del arte del lugar que ocupan y de lo que "hacen" con respecto a lo común" (Rancière, La división 17). Es en este punto en el que se centra este trabajo que indaga cómo el documental del disenso propone otros tipos de reflexión en un entorno en donde los sistemas mercantiles de producción han terminado doblegando la capacidad del cine como espacio político.

Durante los últimos tiempos el cine en Colombia ha tenido puntos de giro contundentes. Después de un largo período de austeridad en la producción cinematográfica, en el 2003, se implementó una nueva ley de cine que amplió y diversificó el espectro de financiación dramáticamente, lo que se vio reflejado en las estadísticas que pasaron de cero películas producidas en 1995 a 35 estrenadas en $2015^{2}$. Al inicio de este periodo la tendencia temática, principalmente en el cine de ficción, se inclinó en representar la violencia en sus facetas más estereotipadas y maniqueístas. Más adelante, la sobreproducción de series de televisión con el mismo tema, que fueron exportadas a todo el mundo, contribuyó a acrecentar aun más la espectacularización de la barbarie que venía siendo promovida por los medios masivos de comunicación. En contraposición, durante

\footnotetext{
${ }^{2}$ Datos sacado de las estadísticas de Proimágenes.
} 
CATEDRAL Tomada: Revista de crítica literaria latinoamericana / Journal of Latin American Literary Criticism El cine de Óscar Campo: memoria de la violencia en Colombia desde el documental del disenso.

este mismo periodo los documentalistas del disenso han trabajado el tema de la realidad colombiana desde una perspectiva divergente y con una propuesta estética perturbadora libre de las narrativas dominantes. De esta manera rompen con el consenso impuesto por los estamentos de poder que, en últimas, son los principales legitimadores de la historia en Colombia. Estas obras tienen dos características comunes: el trabajo desde la periferia geográfica y económica del país y el uso de prácticas documentales como elemento sustancial de sus producciones.

Los documentalistas del disenso no actúan en contextos de producción preestablecidos ni reconocibles y tampoco se identifican necesariamente entre sí. A pesar de trabajar como islas, en conjunto irrumpen en la esfera pública con una postura fuera de la corrección política, con un discurso que se resiste a ser clasificado e instrumentalizado, generador de incomodidad y de razonamientos también disidentes y, por lo tanto, ausente al interior del aparato político preponderante. Con una producción constante desde los años 80, en la que propone el uso de un lenguaje cinematográfico renovado en cada obra, Óscar Campo podría considerarse pionero de este movimiento. El cineasta caleño ha establecido un esquema propio de pensamiento y producción en el marco de la academia que le brinda un espacio de independencia, tanto en su discurso como en su propuesta estética, que le permite ubicar sus películas lejos del lugar común en el que se hallan gran parte de las producciones cinematográficas del país:

Me interesa tomar una serie de decisiones sobre ese mundo que va a aparecer en el documental, sobre la realidad que está allí y que siempre nos llega inicialmente como discurso. $\mathrm{Y}$ a partir de esto entro a trabajar en el campo del documental, sin preocuparme mucho si voy a hacer una cosa innovadora o no, lo que me interesa es hablar de ese mundo que he descubierto, de ese mundo que estoy entendiendo y tratar de hacerlo de la manera más adecuada para que sea entendible o a veces para hacerlo 
opaco. Me interesa que haya un distanciamiento por parte mía y de los espectadores referente al tema. ${ }^{3}$

\section{Perspectiva y subjetividad}

La vida de Óscar Campo, al igual que la vida de la mayoría de los colombianos, ha estado determinada por su relación con la violencia. Sus relatos audiovisuales presentan una visión pesimista sobre el devenir del país y una postura crítica con argumentos contra el sistema, respaldados por una investigación profunda de abordaje académico, algunos de los cuales, con el tiempo, se han vuelto casi proféticos. "En cuanto a la violencia, yo no me considero en una relación de sujeto-objeto, donde el sujeto está mirando, sino que yo hago parte también y estoy tan destrozado como esa realidad que miro". "Sus películas muestran cómo la barbarie no sólo ha dejado huellas profundas en la sociedad colombiana, si no cómo permanece inserta en cada recodo de ésta.

A través de propuestas sincréticas, en las que fusiona el documental con otros modos de expresión, como el cine experimental y el teatro, el cineasta desarrolla una narrativa cargada de símbolos y analogías que hacen parte del ideario colombiano. Con ello logra una ruptura de los cánones estéticos y plantea una manera diferente de pensar la relación entre la subjetividad y el arte. El ensayo es la forma de escritura que elige Campo en la mayoría de sus películas "porque es un discurso sobrio en el que es evidente una preferencia por el conocimiento no ficticio, no narrativo e instrumental, que satisface en su audiencia un deseo de realismo. Su espíritu, su estilo, sus efectos, su sistema de escritura, nos garantizan que el espectáculo no sustituye a la vida, que lo

\footnotetext{
${ }^{3}$ Extracto de una entrevista inédita realizada por la autora a Óscar Campo en la ciudad de Cali en agosto de 2016.

${ }^{4}$ Idem.
} 
CATEDRAL TOMADA: Revista de crítica literaria latinoamericana / Journal of Latin American Literary Criticism El cine de Óscar Campo: memoria de la violencia en Colombia desde el documental del disenso.

representado no es ajeno e incoherente con nuestra experiencia” (Campo, Nuevos 72).

Uno de los factores que más evidencia el disenso de las películas de este director es la dislocación de la perspectiva desde donde es formulado el relato. La violencia en Colombia se ha narrado históricamente desde las víctimas y los héroes del conflicto; al contrario, el director caleño le da voz a seres siniestros, parias y monstruos sociales que se mueven en bajos mundos, paralelos a la sociedad, y que cuentan con sus propias leyes de supervivencia; son sinécdoques de la sociedad colombiana que el director presenta como un mundo no-futuro. Estos personajes, a través de la retórica de su universo interior que también es el del autor, se deconstruyen como sujetos de acciones y dejan testimonio de una época dominada por el "hiperbolismo de la violencia" (Blair 3) mediante tropos como la locura, la enfermedad, las ruinas, los mundos subterráneos y el infierno:

[...] durante muchos años estuvimos haciendo películas donde eran las personas las que hablaban a través de sus opiniones [...] era el otro el que hablaba, pero éramos nosotros también. Estábamos haciendo el montaje, dirigiendo las preguntas, haciendo los encuadres, y en mi caso decidí incluirme en eso. Al principio estetizando los planos y después apareciendo directamente a través de mi voz. Esa relación con el otro es una relación imposible, si es que hay, cuando ese otro es mirado como un bicho al que uno tiene que mirar y darle la cámara, me parece que no tiene mucho sentido. ${ }^{5}$

En "Recuerdos de sangre" (1990), un documental en co-autoría con Astrid Muñoz, se reconstruye el conflicto bipartidista de los años 50 por medio de desgarradores testimonios de asesinos de la época. Uno de los personajes más

\footnotetext{
${ }^{5}$ Extracto de una entrevista inédita realizada por la autora a Óscar Campo en la ciudad de Cali en agosto de 2016.
} 
fuertes del documental era un Pájaro ${ }^{6}$, un matón de la época perteneciente al Partido Conservador. En la película, el hombre re-escenifica las técnicas más eficaces del manejo del revólver, muestra cómo esquivar balas y su destreza con el machete de cuarenta ramales con el que confrontaba a sus enemigos, los liberales. Gracias a este documental, que fue emitido varias veces en la televisión local, el personaje se volvió tan popular que se convirtió en "una especie de héroe monstruoso, un ser de fama para el miedo y la admiración ciudadana, tanto que uno de los mafiosos duros del Cartel de Cali lo llamó para que saliera del puesto de vigilante en un edificio a comandar su escuadrón de guardaespaldas" (Gómez, Palabras).

Más adelante, Campo emprende una serie de retratos de su generación, de la que él se considera un sobreviviente. Los protagonistas son sus alter-egos que revelan el lado oscuro de la ciudad de Cali:

Mis películas son un poco mi conciencia, son mis temores los que aparecen allí. No es sólo la historia y la realidad del país, también es mi propia realidad. Alain Badiou decía que la verdad del cine no estaba en el fotograma ni en el contenido del fotograma, sino en la relación entre las imágenes y en cómo todo lo terrible del Siglo XX se ha mostrado a través de estas relaciones y esas rupturas que han habido entre una imagen y otra con relación al tiempo, a la relación imagen-texto y la relación de esas imágenes con otras imágenes en el pasado. Yo pienso que si hay alguna realidad en lo que he hecho, no proviene de lo que pienso, ni de lo que he mostrado, sino de las relaciones que he planteado allí, que hace que aparezca un tipo de verdad que no creo que sea la verdad consagrada, sino la verdad que surge en relación a ese

\footnotetext{
${ }^{6}$ Se les llamaba así porque después del asesinato huían rápidamente: "volando".
} 
CATEDRAL Tomada: Revista de crítica literaria latinoamericana / Journal of Latin American Literary Criticism El cine de Óscar Campo: memoria de la violencia en Colombia desde el documental del disenso.

acontecimiento tremendo que es la vida de los colombianos durante los últimos años. ${ }^{7}$

La primera producción de esta serie fue "Un ángel subterráneo” (1992), protagonizado por Álvaro Álvarez, un enfermo mental recluido durante más de veinte años en un asilo de locos, ex-drogadictos, ancianos y desahuciados que Campo descubre en una de sus investigaciones académicas. Años después haría “Un ángel del pantano" (1997), donde el personaje principal es su amigo de la juventud Guillermo Lemos a quien, después de muchos años, encontró en la calle destrozado por la droga y la violencia. A través de una narración inducida por preguntas del director, el personaje recorre diferentes espacios de la ciudad y muestra cómo las dos grandes empresas que se gestaron en Cali en los años 80, el cartel de drogas y las guerrillas urbanas, acaban imponiendo una economía y una cultura de la violencia dentro de la ciudad que devastan a cientos de jóvenes, convertidos en soldados de sus causas. Muestra desde adentro y desde muy cerca una realidad aterradora por fuera del discurso esperanzador del cine hegemónico y los programas de televisión que intentan convencer a los colombianos que están en el país más rico y más feliz del mundo.

Este viaje a lo subterráneo de la ciudad avasallada por la barbarie continuaría con "El proyecto del diablo" (1999), tal vez el más representativo de sus documentales. Hoy, después de veinte años de su realización, esta película se posiciona como una obra de referencia en la que muchas de las ideas que plantea el autor se mantienen vigentes y admiten sucesivas lecturas a través del tiempo, siempre lúcidas, de la realidad caleña. Esta película difícilmente podría ser enmarcada dentro de un modo de representación diferente al de documental de disenso por varias razones. Durante veinticuatro minutos, en una puesta en escena dispuesta como un teatro, "La Larva", un hombre que hizo pactos indiscriminados con narcotraficantes, asesinos y militantes en Colombia y Estados Unidos,

${ }^{7}$ Extracto de una entrevista inédita realizada por la autora a Óscar Campo en la ciudad de Cali en agosto de 2016. 
interpreta un monólogo escrito en co-autoría con el cineasta. Los pensamientos y las palabras de Campo salpican una narración que, poco a poco, va llevando al espectador a las profundidades de las cloacas de Cali, donde el personaje permanece sin saber si está vivo o muerto. Preso de su pasado y en un presente a modo de basurero infestado de agua podrida, insectos, muros destruidos y restos de máquinas, el personaje permanece en completa soledad, salvo por sus demonios que lo persiguen y no le permiten librarse de sus miedos, culpas y paranoias. Él dice ser un cáncer del 56, el mismo año en el que nació Campo en plena guerra bipartidista: "Nací en un torbellino de una explosión que destruyó a Cali, ciudad donde vivo... Vengo de mala sangre, de gente del campo, oscura y encorvada sobre la tierra, ajenos a cualquier arte que no sea la bala y el machete [...] De mi padre dicen que mató algunos de la época de Laureano ¿Será por eso que tengo la sangre caliente?". 8

Esta película marca el cierre de una época y el comienzo de otra; coincide con el fin del milenio. Cuando Colombia mira con optimismo los visos de una posible paz con los grupos subversivos, Campo muestra una sociedad sometida por la violencia.

Este ensayo audiovisual sería la génesis de su primer largometraje, "Yo soy otro" (2010), en el que Campo se sale de su género natural, el documental, y hace una ficción que parece no lograr el nivel de fluidez de sus anteriores producciones, aunque mantiene cohesión con los conceptos que viene trabajando desde décadas atrás y que revelan, detrás del argumento, a una persona que ha venido pensando profundamente la realidad del país. José González, el protagonista de la película, es un hombre que se mueve en un círculo muy limitado y que un día descubre que su cuerpo está lleno de llagas; a partir de ese momento comienza a experimentar una serie de cambios que lo obligan a salir de su comodidad. Es así como empieza a descubrir la ciudad y con ella una serie de hombres idénticos a él que padecen sus mismos síntomas.

${ }^{8}$ Extracto del monólogo dicho por Fernando Córdoba en el documental El proyecto del diablo de Óscar Campo 
CATEDRAL Tomada: Revista de crítica literaria latinoamericana / Journal of Latin American Literary Criticism

El cine de Óscar Campo: memoria de la violencia en Colombia desde el documental del disenso.

Campo continua su aproximación a la realidad desde una perspectiva apocalíptica y repite la metáfora de la enfermedad como la representación de la maldad y la descomposición moral que impera; retrata a un país trastornado que engendra seres trastornados en una sociedad alineada a los discursos hegemónicos. El origen y causa de la enfermedad simbolizan los instrumentos que usan los diferentes bandos de poder para manipular y confundir a la opinión pública, responsabilizándose los unos a los otros.

La subjetividad es el eje principal del argumento; el desdoblamiento del ser humano que muestra las diferentes conciencias con las que conviven los colombianos y que en la película intentan aniquilarse entre sí: el subversivo, el paramilitar, el narcotraficante, el indigente y el burgués:

En vez de una narración gobernada por la causalidad, Campo elige de nuevo la creación de metáforas y la expresión alegórica que le permite separarse, a la vez, del objetivismo y el subjetivismo: la analogía entre los virus y la violencia, el descenso a las profundidades, las sectas y las conspiraciones, las alusiones a la leyenda fáustica para hablar de una generación que cambió su alma por las quimeras del éxito y el desarrollo. (Zuluaga 125)

\section{Academia e independencia}

Un aspecto fundamental de la vida de Campo y que incide directamente en sus películas, es su relación con la academia. El cineasta ha pasado casi toda su vida en la Escuela de Comunicación Social de la Universidad del Valle, primero como estudiante y luego como profesor. El pertenecer a una institución podría verse como un factor contraproducente para la independencia creativa y argumentiva del director, pero paradójicamente esto le brindó un espacio que le 
permitió consolidar su mirada filosófica y disidente sobre la realidad del país. Pues durante la última década las universidades públicas en Colombia centraron sus objetivos en fortalecer su derecho a la autonomía universitaria, derecho protegido por la constitución nacional, el cual favorece el libre intercambio de ideas, la búsqueda desinteresada del conocimiento y la verdad alejada de las coerciones del mercado y de la visiones y prácticas sobre el Estado que tienen los actores políticos de turno. Esta pugna procura hacer de la Universidad el templo de la libertad incondicional de palabra y de cuestionamiento, como contraposición al pensamiento superficial y ligero de la mayoría de los medios de comunicación en Colombia, así como al inmenso poder por parte de los grupos políticos y económicos que circula a través de ellos.

La Escuela de Comunicación, fundada por el filósofo Jesús Martín Barbero, nace como un proyecto moderno en el sentido de idear lo académico y el hacer universitario como un hacer social, cuyo cometido final sea la generación del cambio. La filosofía con la que se cimentó esta institución recalca la importancia de la incidencia social de la academia, de la investigación y de los procesos artísticos/culturales, los cuales se deberían ver reflejados en la autonomía de los medios y las diferentes formas expresivas. Campo se convirtió en pilar de este pensamiento y lo promulga en el área de audiovisuales de la Escuela.

En los años 90, ante el recrudecimiento de la violencia proveniente de los diferentes frentes por la infiltración del narcotráfico en todos los sectores de la sociedad, surge la necesidad de volver la mirada a la realidad desde los diferentes discursos autónomos que aluden a lo social, entre ellos el documental. Mientras el principal financiador de la industria cinematográfica en Colombia, Focine, es liquidado, en el seno de la Universidad del Valle nace liderado por Óscar Campo la serie documental "Rostros y Rastros" (1988-2000) $)^{9}$, la cual fue emitida en el Canal Regional Telepacífico de manera ininterrumpida durante doce años y que

\footnotetext{
${ }^{9}$ Cfr. http://cms.univalle.edu.co/rostrosyrastros/
} 
CATEDRAL Tomada: Revista de crítica literaria latinoamericana / Journal of Latin American Literary Criticism El cine de Óscar Campo: memoria de la violencia en Colombia desde el documental del disenso.

desde el 2016 se retomó con el nombre de "Rostros y Rastros. Nueva Generación”. El formato de producción y realización diseñado para esta serie le permite a la academia acercarse a temas imposibles de trabajar en una productora comercial. Este auge del documental en Cali ocurre en un momento en el que el cine no sólo no cuenta con recurso económico, también, según Óscar Campo, cuando se ha agotado el discurso que ficcionalizaba la ciudad, lo que contribuye a que los cineastas, los viejos y los nuevos, vuelquen sus ideas en "Rostros y Rastros". Por ese primer ciclo pasaron desde maestros como Carlos Mayolo, Luis Ospina y Antonio Dorado, algunos pertenecientes al llamado Grupo de Cali o Caliwood, hasta estudiantes de aquella época que hoy grandes cineastas como Juan Carlos Gil, Jorge Navas y Carlos Moreno.

Con esta ventana de emisión se estimula la producción documental que se vuelve sistemática. En ese entorno, Campo propone un tipo de escritura audiovisual en la que plantea una relación transgresora entre imágenes, textos y acontecimientos. El cineasta explica que su método consiste en:

Tratar de adecuar esos (los) contenidos que van surgiendo desde el pensamiento académico a esas (las) posibilidades expresivas. Ahí es donde yo he estado mediando: esa relación entre escrituras y el material que surge de mirar la realidad colombiana de una manera compleja, a través de la antropología, de los estudios culturales. El trabajo ha consistido en estar atento a los que se produce intelectualmente, a sus avanzadas, ayudar a renovar bibliografías (que ya el profesorado lo hace por su cuenta también) para poder encajar una cosa con otra. Eso ha generado una serie de monstruos visuales pero de tanta ensayadera se han logrado un par de cosas. (Suárez 11)

Gracias a su papel como docente y orientador durante más de veinticinco años, Campo se ha convertido en un motor renovador del cine nacional, ha influenciado a decenas de estudiantes que en la actualidad son los directores, 
productores, cineclubistas e investigadores que están marcando la presencia del cine colombiano en el ámbito internacional.

La Universidad, en cierto modo, ha sido para él una trinchera donde refugiar su independencia y desde donde lanzar sus ideas disidentes. Donde además su trabajo se enriquecido por un ambiente que le permite confrontar ideas y argumentos con intelectuales provenientes de las ciencias sociales, la antropología, la etnografía y la psicología. Debemos agregar que, por otro lado, la marginalidad de Campo también se refleja en su autoimposición por mantenerse fuera de los ámbitos formales de financiación y circulación de sus proyectos cinematográficos y de su terca permanencia en la ciudad de Cali, la periferia de un país periférico, ciudad en la que ha vivido siempre, lo cual denota una relación más que comprometida con su realidad. Allí nació, al igual que los personajes de sus películas, y allí ha tenido una vida que oscila entre mundos contradictorios: un ambiente familiar de fervor religioso, con madre ex-monja y padre seminarista; el universo académico de la universidad pública; y una ciudad en ruinas. Esto ha hecho que sea inevitable que sus películas se desarrollen en su entorno inmediato, sin embargo, los temas que le preocupan, como a muchos intelectuales del mundo occidental con quienes Campo mantiene un permanente diálogo a través de sus lecturas y disertaciones, son el capitalismo y la violencia, tópicos que están obsesivamente presentes en sus obras.

\section{Removiendo estructuras}

En la búsqueda por trabajar diferentes modos de subjetividad, en su película "Cuerpos Frágiles" (2011) Campo asume la narración en primera persona con un discurso anti-hegemónico con el que da re-significado a imágenes de noticiero, recopiladas durante más de dos años, que relatan el conflicto armado colombiano. Con argumentos sólidos el cineasta transita en un terreno en disputa, 
CATEDRAL TOMADA: Revista de crítica literaria latinoamericana / Journal of Latin American Literary Criticism

El cine de Óscar Campo: memoria de la violencia en Colombia desde el documental del disenso.

como es el de la imagen, para acercarse a los procesos reales del país y generar una posición distante de lo establecido.

En esta película Campo confronta el discurso de poder de los medios de comunicación poniendo en evidencia su manipulación, superficialidad y fugacidad. El autor induce a sospechar de los discursos mediáticos totalizantes que circulan en la cotidianidad y que determinan el consenso ideológico del país. El texto de la película hace énfasis en la relación entre la ideología y los medios y resalta el papel que tienen éstos como actores fundamentales en el conflicto por su capacidad de promover en la sociedad colombiana, de por si fuertemente polarizada, debates que instigan a la movilización colectiva en defensa de propuestas político-militares del gobierno de turno. Son máquinas de producir espectros, como dice Jacques Derrida.

Este documental pone sobre el tapete el tema de la ética y la fragilidad humana en una sociedad devastada por una guerra por el poder que se libra, no solo en lo factual, también en los simbólico. Las marcas de la barbarie se hacen evidentes en el cuerpo y en la psiquis de cada ciudadano, transformándolo muchas veces en una víctima sin identidad, ni historia:

La realidad es algo denso de lo que nosotros también hacemos parte, está atravesada por capas de significación, por discursos y en el momento en que uno hace un documental es un encuentro temporal con lo que llamamos realidad pero no es nada claro. Uno intenta tratar de entender sobre eso real que está investigando, pero con mucha conciencia de su limitación, es una conciencia sobre la posibilidad de no entender completamente lo dado. ${ }^{10}$

\footnotetext{
${ }^{10}$ Extracto de una entrevista inédita realizada por la autora a Óscar Campo en la ciudad de Cali en agosto de 2016.
} 
Campo muestra cómo en la sociedad colombiana existe una desarticulación entre el orden de lo real y la conciencia; el pensamiento y el lenguaje. Expone la existencia de una realidad que va mucho más allá de la posibilidad de comprensión de la mente humana.

En un principio la película se centra en el cuerpo casi destrozado del líder insurgente Raúl Reyes que es exhibido por el gobierno como un trofeo de guerra. En Colombia se repetía el ícono global de los cuerpos exhibidos sin pudor y sin culpa tras el argumento de que lo merecían. Esta imagen saturó durante meses la televisión y los periódicos del país. El cineasta buscaba producir un efecto de encuentro y de claridad hacia esa realidad a través de un discurso personal en el que plantea preguntas que llevan a reflexionar sobre qué pasa, por qué y cuáles son las consecuencias. “¿Por qué los gobernantes de un estado que supuestamente protege la vida, tienen que bombardear, violar la soberanía de otro estado y causar la muerte para defender la sociedad?" (Campo, Cuerpos 19).

Campo se dirige a una sociedad aletargada y con sus discursos perturbadores busca despertarla, como lo hizo Farocki con su gesto en la película "Fuego inextinguible" (1969) cuando se autoinflinge ante la cámara una quemadura en su brazo con un cigarrillo para mostrar la dimensión de los efectos del Napalm como una toma de posición pública del artista. Didi-Huberman dice:

Como si se hubiese vuelto necesario, en nuestras condiciones históricas actuales, atreverse verdaderamente a "poner (legen) las manos al fuego" para entender mejor, para leer (lesen) mejor este mundo a causa del cual padecemos - este mundo del que debemos afirmar, repetir, declarar, que es a partir del cual estamos padeciendo- y así y todo nos negamos a padecer (leiden). ( 21)

En un país como Colombia, donde la comprensión de la realidad está supeditada a fuertes pilares hegemónicos sostenidos por la espectacularización de 
CATEDRAL TOMADA: Revista de crítica literaria latinoamericana / Journal of Latin American Literary Criticism El cine de Óscar Campo: memoria de la violencia en Colombia desde el documental del disenso.

lo mediático y lo comercial, propuestas estéticas como las de Óscar Campo vislumbran la existencia de un cine, el documental del disenso, que remueve las estructuras dominantes y que está cimentado en la independencia de los procesos de producción y de pensamiento que discrepa de aquellos que responden a las políticas del momento. Desde la marginalidad, no solo geográfica también económica, el documental del disenso busca establecer un nuevo orden para explicar la realidad y así irrumpir en lo establecido proponiendo construir una nueva conciencia. Es una propuesta minimalista que centra su construcción en argumentos intelectuales que plantean nuevos interrogantes, lo que significa elaborar un texto audiovisual más complejo: las investigaciones son largas y meticulosas, cercanas a los métodos etnográficos, para compensar los pocos días de producción. Es así como desde este nuevo escenario se irrumpe en el consenso político para presentar opciones provocadoras que invitan a re-pensar la realidad contemporánea colombiana que discrepa con la lógica de información de los medios. En una época de imágenes sin fin, se hace necesario detenerse y hacer una mirada reflexiva del presente, como dice la argentina Laía Quílez: "Nos encontramos, pues, en una situación que, si bien impide un transcurrir acelerado y teleológico del presente, aviva una memoria que se esfuerza en darle consistencia a ese presente fugaz que se volatiliza sin descanso" (44).

Las películas de Campo, junto con otras propuestas de documentalistas que están en la misma búsqueda como Camilo Restrepo, Juan Soto y Claudia Salamanca, permiten analizar de manera coherente, profunda, crítica y desde el disenso los conflictos por los que ha atravesado Colombia. Al estar completamente desligados se las narraciones de poder del momento, estos relatos otorgan un entendimiento de la realidad que traspasa el tiempo y el espacio. Además, ponen en evidencia las marcas de la violencia que están en el interior de la sociedad, las cuales se ven reflejadas, a veces, de manera inaceptable o incomprensible en un sin fin de barbarie. Estas películas narran desde un tiempo presente, lo que nos lleva a pensar que si bien el documental del disenso plantea una manera diferente de pensar el país en el aquí y el ahora, también construye 
una memoria que en la distancia brindará lecturas que permitirán entender la realidad compleja de este Colombia.

\section{Bibliografía}

Barbero, Jesus Martín. Medios: olvidos y desmemorias. Conferencia en Tertulia Medios para la Paz. Fundación Santillana Bogotá, noviembre de 1998.

- "Mutaciones culturales y estéticas de la política". Revista de estudios sociales, de la facultad de ciencias sociales. 2010. Bogotá: Universidad de los Andes: 15-25.

Berdiel, Otto. “La obra de Oscar Muñoz: Lo desaparecido no está ausente » 2013. Disponible en: http://psicoanalisisypolitica.blogspot.com.co/2013/02/laobra-de-oscar-munoz-lo-desaparecido.html. Última consulta: 19 abril 2017.

Blair, Elsa. Muertes violentas:la teatralización del exceso. Medellín: Editorial Universidad de Antioquia, 2004.

Campo, Óscar. Cuerpos frágiles. Sin publicar, 2010.

- "Nuevos escenarios del documental en Colombia". Kinetoscopio n ${ }^{\circ} 48$, vol. IX, Medellín: Centro Colombo Americano, 1998: 74.

Didi-Huberman, Georges. "Prólogo". FAROCKI, Harun. Desconfiar de las imágenes. Buenos Aires: La caja negra, 2013.

GMH. Basta ya! Colombia memoria de guerra y dignidad. Bogotá: Imprenta Nacional, 2013.

Gómez, Santiago. "Palabras sobre Óscar Campo" Madera Salvaje. Marzo 2012. Disponible en http://maderasalvaje.blogspot.com.uy/2012/03/palabrassobre-Óscar-campo-2-entrega.html. Última consulta: 15 de mayo 2017.

González, Fernán. "La violencia política y las dificultades de la construcción de lo público en Colombia: una mirada de larga duración”. En: Jaime Arocha, Fernando Cubides y Myriam Jimeno (Comp.), Las violencias: inclusión creciente. Bogotá: Centro de Estudios Sociales, Universidad Nacional de Colombia, 1998.

Huyssen, Andreas. En busca del futuro perdido. Cultura y memoria en tempos de la globalización. Madrid: S.L. Fondo de Cultura Económica de España, 2002.

Medina, Álvaro. Arte y violencia en Colombia desde 1948. Bogotá: Museo de Arte Moderno de Bogotá, 1999.

Niño, Alejandra. "Estéticas contemporáneas: aproximaciones y perspectivas". Revista AdVersuS, VIII, 19-20, diciembre 2010 - junio 2011:64-80. 
Quílez, Laia. La representación de la dictadura militar en el cine documental argentino de segunda generación. Tarragona: Tesis doctoral, Departamento de Estudios de Comunicación, Universitat Rovira i Virgili, 2009.

Rancière, Jacques. La División de lo sensible, Salamanca: consorcio Salamanca, 2002.

. Sobre políticas estéticas, Barcelona: Museo d'Art Contemporani de Barcelona y Servei de Publicacions de la Universitat Autònoma de Barcelona. 2005.

Política, policía y democracia. Santiago: editorial LOM, 2006.

Rubiano, Elkin. "Las formas políticas del arte: el encuentro, el combate y la curación”. Revista Ciencia Política 9. 1 (junio 2014): 70-86.

Suárez, Juana. Óscar Campo: La inquietud visual ente la sospecha del éxito. Publicación 10 años de Lugar a dudas. Cali, 2015.

Zuluaga, Pedro Adrián. "La paranoia como fin de la historia". Revista Rencontres. Cinémas d'Amérique Latine de Toulouse n. 17. 2009 : 124-134. 